\begin{tabular}{|cc|}
\hline STOVE & SMOKE \\
COMBUSTION & PYROLYSIS \\
PHENOLS & HEALTH \\
BENZENE & PAH \\
ANALYSIS & GC - MS \\
\hline
\end{tabular}

Open access final manuscript version of Environmental Technology 22 (2001) 391-395 Link to publisher

\title{
Phenols and aromatic hydrocarbons in chimney emissions from traditional and modern residential wood burning
}

Jennica Kjällstrand and Göran Petersson

Related articles on specific emissions from wood burning:

Phenolic antioxidants in wood smoke

Volatile hydrocarbons from domestic wood burning 


\title{
PHENOLS AND AROMATIC HYDROCARBONS IN CHIMNEY EMISSIONS
}

\section{FROM TRADITIONAL AND MODERN RESIDENTIAL WOOD BURNING}

\author{
JENNICA KJÄLLSTRAND AND GÖRAN PETERSSON* \\ Department of Chemical Environmental Science, Chalmers University of Technology, \\ 41296 Göteborg, Sweden, E-mail address: goranp@kmv.chalmers.se
}

\begin{abstract}
The emissions from a traditional tiled stove consisted mainly of lignin-related methoxyphenols with antioxidant properties, and 1,6-anhydroglucose from cellulose degradation. A wood stove of presently introduced energy-efficient design for residential heating and hot-water supply was shown to emit small amounts of methoxyphenols and anhydrosugars from primary wood pyrolysis. Secondary harmful components like benzene and polycyclic aromatic hydrocarbons constituted a major portion of the organic emissions. It is concluded that differences in smoke composition are essential to consider in recommendations and rules for proper choices of wood burning devices.
\end{abstract}

Keywords: Wood smoke, combustion, gas chromatography, air pollutants, health hazards

\section{INTRODUCTION}

New technical systems for residential wood burning are now recommended and rapidly introduced in Sweden and many other countries. Major incentives are increased energy efficiency and decreased total emissions of gaseous and particulate organic compounds. Correspondingly decreased environmental and health hazards are not self-evident, however, because the proportions between major groups of compounds from pyrolysis of wood and wood components depend heavily on temperature [1]. 
Wood smoke represents a complex mixture of compounds with widely varying effects. Primary major components from combustion of lignin in wood are methoxyphenols [2,3], which possess antioxidative properties [4,5]. The wood polysaccharides give rise to 1,6-anhydroglucose $[1,6]$. Health concerns presently emphasise the carcinogenic benzene, which is emitted as a major volatile hydrocarbon [7]. Many studies have focussed on particle-associated polycyclic aromatic hydrocarbons $[8,9,10]$, which include several carcinogenic species.

The purpose of this study was to determine the proportions of major hazardous and non-hazardous compounds and compound classes in chimney smoke. Differences in proportions between traditional and new burning devices should be important for decisions on the introduction of new systems and were therefore emphasised.

\section{MATERIALS AND METHODS}

The commercial stove for household hot-water supply and hot-water house heating (Egor V25, model FG) had a cast iron furnace $(1281,32 \mathrm{~kW})$ with horizontal air flow during combustion. The stove was linked to two 5001 hot-water storage tanks. An igniting period of $5 \mathrm{~min}$ was followed by loading once only, with $20 \mathrm{~kg}$ of season-dried wood. The air flow was decreased automatically as the intensity of the fire decreased. In the traditional tiled stove, about $1 \mathrm{~kg}$ of dry birchwood was used as fuel. Repeated fires, with warmed-up stove and chimney, were arranged identically.

Analytical Data

Adsorbent cartridge : Injector glass liner filled with Tenax TA, 60-80 mesh, $0.1 \mathrm{~g}$

Samples : Withdrawn using a conventional air pump, $3 \mathrm{ml} \mathrm{min}^{-1}$

Desorption : Thermal, in the injector, $220^{\circ} \mathrm{C}$

Gas chromatograph : Varian 3800, with helium as carrier gas, $1.1 \mathrm{ml} \mathrm{min}^{-1}$

Column $\quad: 30 \mathrm{~m} \times 0.25 \mathrm{~mm}$ i.d. FSOT (fused silica open tubular)

Stationary phase $\quad$ : Cyanopropylphenylsilicone, Rtx 1701, $0.25 \mu \mathrm{m}$ phase layer 
Oven temperature : Increased $10^{\circ} \mathrm{C} \min ^{-1}$ from $-50^{\circ} \mathrm{C}$ to $50^{\circ} \mathrm{C}$ and then $5^{\circ} \mathrm{C} \mathrm{min}^{-1}$ to $250^{\circ} \mathrm{C}$

Mass spectrometer : Varian Saturn 2000 , ion trap $\left(120^{\circ} \mathrm{C}\right)$, EI ionisation $(70 \mathrm{eV})$

Mass spectra $\quad$ : Mass range $m / z$ 35-400, one spectrum $\mathrm{s}^{-1}$ recorded and data-stored

Quantitative data $\quad$ : From integrated peak areas in the total ion current chromatogram

\section{RESULTS AND DISCUSSION}

The results given in Table 1 illustrate the content of specific compounds in smoke for differing burning conditions. The condensed results in Table 2 emphasise the striking differences for five major compound classes.

Smoke Samples

The first four samples reported in Table 1 were taken during typical burning cycles of an energyefficient system of recent design. The sampling time was in the interval 3-7 min for each sample. The first sample represents the igniting phase with mainly small roundwood. The second sample refers to initial burning of coarse wood which was put into the furnace $5 \mathrm{~min}$ after igniting as the single load for the burning cycle. The fuel was mainly hardwood (birch, alder, oak and aspen) with about one third of softwood (pine and spruce). The third sample was taken during full flaming combustion, and the fourth when flaming was replaced by glowing combustion only.

The last two samples represent smoke from a traditional tiled stove originally intended for warming one room of a house. A small fire of birchwood only was used, as is often the case nowadays when tiled stoves and fireplaces are used for pleasure burning. The last column refers to a first reluctant spring morning fire, and the second last column to a subsequent hotter fire with warmer stove and chimney. The burning cycles from igniting to ceased flaming were $12-15 \mathrm{~min}$, and samples were taken during this period.

For both types of stoves, samples were taken in the chimney pipe outlet. The representativity of the samples was checked by samples from duplicate or multiplicate burning cycles. 
Table 1. Concentrations $\left(\mathrm{mg} \mathrm{m}^{-3}\right)$ of selected compounds in chimney smoke from residence wood burning.

\begin{tabular}{|c|c|c|c|c|c|c|}
\hline & \multicolumn{4}{|c|}{$\begin{array}{c}\text { Modern stove for hot-water supply } \\
\text { Four sampling occasions during the burning cycle }\end{array}$} & \multicolumn{2}{|c|}{$\begin{array}{c}\text { Tiled stove } \\
\text { Total burning cycle }\end{array}$} \\
\hline & $5 \mathrm{~min}$ & $12 \mathrm{~min}$ & $30 \mathrm{~min}$ & $90 \mathrm{~min}$ & Warm stove & Cold stove \\
\hline \multicolumn{7}{|l|}{ Volatile hydrocarbons } \\
\hline Benzene & 18.3 & 41.0 & 46.7 & 3.5 & 2.59 & 0.24 \\
\hline Methylbenzene & 6.1 & 12.3 & 11.7 & 2.2 & 0.83 & 0.14 \\
\hline Styrene & 3.0 & 6.3 & 5.4 & 0.9 & 0.46 & 0.06 \\
\hline \multicolumn{7}{|l|}{ Polycyclic hydrocarbons } \\
\hline Naphthalene & 8.8 & 23.5 & 22.1 & 0.9 & 0.76 & 0.08 \\
\hline Phenanthrene & 2.6 & 21.5 & 20.0 & 1.5 & 0.14 & 0.01 \\
\hline Pyrene & 2.7 & 20.8 & 24.2 & 1.3 & 0.07 & 0.01 \\
\hline \multicolumn{7}{|l|}{ Phenol and alkylphenols } \\
\hline Phenol & 3.5 & 9.4 & 14.2 & 1.7 & 0.27 & 0.05 \\
\hline 2-Methylphenol & 0.9 & 3.3 & 3.3 & 0.7 & 0.11 & 0.02 \\
\hline 3-Methylphenol & 1.3 & 5.8 & 5.0 & 1.3 & 0.15 & 0.03 \\
\hline \multicolumn{7}{|l|}{ Methoxyphenols } \\
\hline 4-Methyl-2-methoxyphenol & 0.7 & 0.3 & 0.4 & 1.2 & 0.22 & 0.04 \\
\hline 4-Methyl-2,6-dimethoxyphenol & 1.2 & 1.3 & 0.8 & 3.9 & 0.59 & 0.23 \\
\hline 4-(1-Propenyl)-2,6-dimethoxyphenol $(E)$ & 0.7 & 0.3 & 0.4 & 3.0 & 0.48 & 0.24 \\
\hline 4-(2-Oxopropyl)-2,6-dimethoxyphenol & 1.3 & 0.3 & 0.8 & 2.2 & 0.28 & 0.30 \\
\hline \multicolumn{7}{|l|}{ Carbohydrate-derived compounds } \\
\hline 2-Furaldehyde & 1.6 & 3.4 & 1.8 & 3.7 & 1.39 & 0.23 \\
\hline 1,6-Anhydroglucose & 8.3 & 0.8 & 2.9 & 3.1 & 0.94 & 0.67 \\
\hline
\end{tabular}


Table 2. Percentage proportions of selected compounds in chimney smoke from residence wood burning.

\begin{tabular}{|c|c|c|c|}
\hline & \multicolumn{2}{|c|}{ Water-heating furnace } & \multirow{2}{*}{$\begin{array}{l}\text { Tiled stove } \\
\text { flaming }\end{array}$} \\
\hline & flaming $^{a}$ & glowing $^{a}$ & \\
\hline Benzene & 35 & 8 & 16 \\
\hline Phenanthrene, Pyrene & 33 & 6 & 1 \\
\hline Phenol, Alkylphenols ${ }^{b}$ & 24 & 15 & 6 \\
\hline Methoxyphenols ${ }^{c}$ & 4 & 56 & 52 \\
\hline 2-Furaldehyde, 1,6-Anhydroglucose & 4 & 15 & 25 \\
\hline
\end{tabular}

${ }^{\mathrm{a}}$ Results for samples 3,4 and $5+6$ in Table 1 .

${ }^{\mathrm{b}}$ Includes methylphenols, ethylphenols and dimethylphenols.

${ }^{\mathrm{c}}$ Includes about 20 assessed 2-methoxyphenols and 2,6-dimethoxyphenols. 


\section{Compound Classes}

Results are given for selected major compounds within each of five compound classes. This permits differences in proportions related more to compound class than to specific compounds to be seen more clearly.

Among the volatile aromatic hydrocarbons, benzene is predominant. The highest concentrations and the highest proportions compared to other smoke components were obtained for full flaming burning in the water-heating stove. The much lower concentration of methylbenzene (toluene) is in accordance with results from specific studies of volatile hydrocarbons [7]. The concentration of styrene was typically higher than that of ethylbenzene and the three dimethylbenzene (xylene) isomers.

The polycyclic aromatic hydrocarbons (PAH) phenanthrene and pyrene were emitted in very high concentrations and proportions from hot flaming burning. In contrast, their proportions from initial, glowing, and tiled stove burning were much lower. This is consistent with observed extensive formation of PAH from wood above $800^{\circ} \mathrm{C}$ but not below $600^{\circ} \mathrm{C}[1,10,11]$. The proportions of the bicyclic and more volatile naphthalene were large but varied less strikingly. Observed compounds formed in smaller amounts were indene, acenaphthylene, methylnaphthalenes and anthracene. Fluoranthene was formed in similar proportions as its isomer pyrene. These two compounds are normally included in studies of PAH species of lower volatility [8,9] permitting estimates of species not included in this study.

Phenol is emitted as a prominent component, particularly in smoke from the large burning device. The three isomeric methylphenols add up to about the same proportion as phenol. The three isomeric ethylphenols and several isomeric dimethylphenols were smaller components. Similar proportions between phenol and alkylphenols have been reported in chimney studies of wood smoke by other methods [2].

Four prominent methoxyphenols were selected as representatives of this numerous compound class. Their proportion was low for hot flaming combustion, but high in smoke from the tiled stove. The methoxyphenols are formed in high proportions from incomplete burning, as primary degradation products of plant lignin [3]. Both softwood and hardwood give rise to 2-methoxyphenols, whereas 2,6- 
dimethoxyphenols are obtained in large proportions from hardwood only. The four methoxyphenols in Table 1 add up to about $40 \%$ of the total amount of about 20 quantitatively significant methoxyphenols. The proportions given in. Table 2 refer to the total amount of methoxyphenols. The proportions between specific methoxyphenols varied with combustion conditions, but were similar to those reported in an American study of chimney wood smoke [2]. The results in Table 2 are consistent with reported maximum proportions at lower temperatures for methoxyphenols than for the phenols without methoxyl groups $[1,10]$.

Polysaccharide degradation gives rise to 1,6-anhydroglucose and 2-furaldehyde as major compounds in smoke from incomplete burning. Their proportions are much lower for efficient burning, paralleling the results for methoxyphenols. The presence of a large proportion of 1,6-anhydroglucose in biomass smoke is generally recognised $[1,6]$. The more volatile 2-furaldehyde is easily lost in studies of smoke particles. High proportions of 2-furaldehyde relate to a high content of xylan hemicelluloses in birch and other hardwood species [1].

Health Hazards Relative to Burning Conditions

Concern regarding health hazards of wood smoke is focussed on the carcinogenic volatile hydrocarbon benzene and on the polycyclic aromatic hydrocarbons. Phenanthrene and pyrene are well known PAH representatives. In Table 2, the relative proportions of these compounds are compared with those of other prominent compound classes for the burning conditions studied. The proportions of the hazardous compounds are highest in smoke from flaming combustion in the modern stove for hot-water supply. The proportions are much lower in smoke from the tiled stove and from glowing combustion. Contrary to the hazardous hydrocarbons, the methoxyphenols are almost completely destroyed by the efficient burning device. On the other hand, they constitute as much as half of the amount of recorded compounds in smoke from the tiled stove. The methoxyphenols include vanillin and structurally related pleasant compounds [2,3]. They have antioxidant properties [4,5], which may even counteract hazardous effects of the smoke. The 2,6-dimethoxyphenols from hardwood are stronger antioxidants than the 2-methoxyphenols from softwood [4], with potential consequences for the health impact of 
smoke from different wood fuels. On efficient burning, the methoxyphenols are partly replaced by phenol and alkylphenols, which have weaker antioxidant effects. The prominent 1,6-anhydroglucose from incomplete burning is not associated with health hazards either.

Phenols have actually been shown to decrease a carcinogenic effect of the best known PAH, benso(a)pyrene [12]. Furthermore, extracts of ambient air particles have been demonstrated to be less carcinogenic for wood smoke than for traffic exhaust [13]. These observations may be linked to the content of methoxyphenols in wood smoke. Methoxyphenols are obviously emitted during the initial igniting and the final glowing phases of wood burning, even for stoves with high combustion temperature. Newsprint from thermo-mechanical softwood pulp is often used for igniting, and gives rise to smoke differing markedly from that of softwood by a high proportion of coniferyl alcohol, 3-(4hydroxy-3-methoxyphenyl)-2-propenol [14].

Based on recorded large decreases in the total amount of emitted carbon-containing material, stoves with more efficient burning are now strongly recommended. An environmentally approved version with ceramic furnace and still higher combustion temperature is available for the commercial stove studied. Devices with hot-water storage tanks, like the one studied, permit energy-efficient burning with full effect on few occasions. Traditionally, intermittent burning with lower temperature and effect has been used. The results presented demonstrate that the total emitted amount of organic material may be a misleading parameter when health hazards are considered. Specific comparisons of emissions of benzene, PAH and methoxyphenols should be preferable.

\section{Analytical Aspects}

The use of Tenax adsorption cartridges and small sampling volumes permits simultaneous determination of the important volatile hydrocarbon benzene and a variety of semi-volatile compounds. This is essential when results are needed for comparisons of health hazards of emissions from different stove devices, wood fuels and burning techniques. Potential break-through of benzene on sampling is easily checked by duplicate samples with different sampling volumes. 


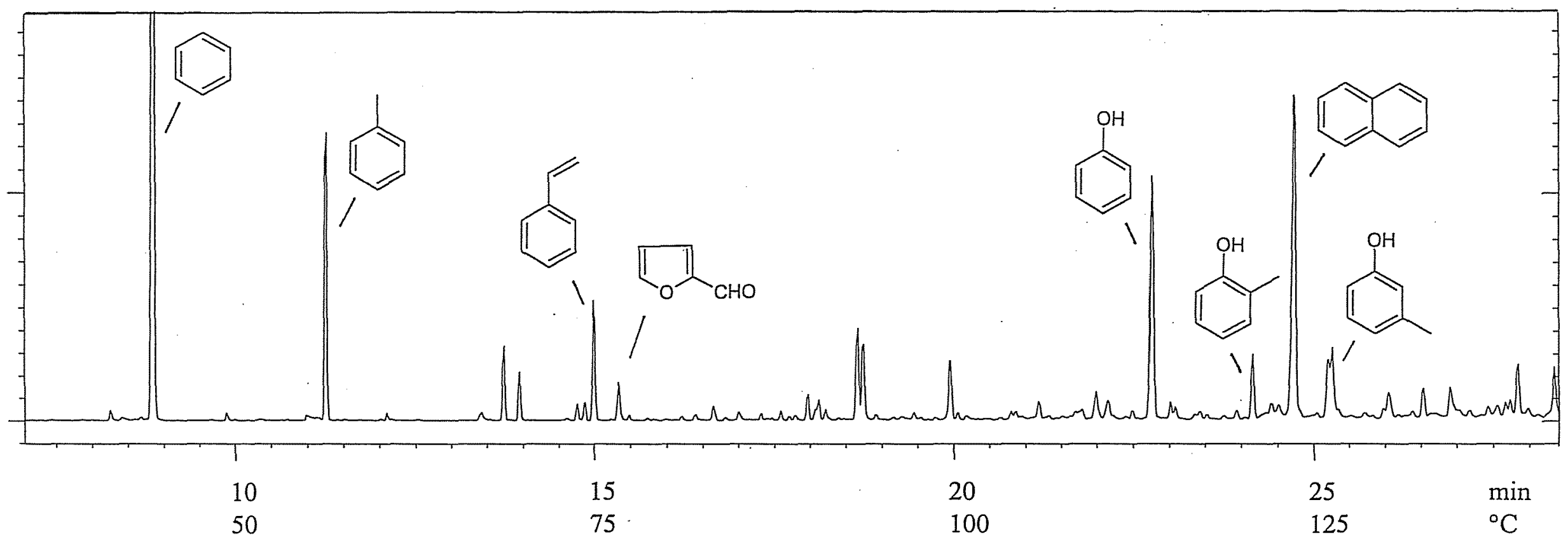

Figure 1.

Total ion current chromatogram of early-eluting compounds in chimney smoke from fully flaming wood stove burning (third column in Table 1). 
The chromatogram in Figure 1 demonstrates good chromatographic behaviour of hydrocarbons as well as very polar compounds, like phenols and 2-furaldehyde, on the cyanopropylphenylsilicone fused silica capillary column. Less volatile compounds like PAH and methoxyphenols [3] appear in a latter part of the chromatograms. The differences in response factors were small compared with the impact of burning conditions, and the response determined for vanillin was therefore used for all compounds [3]. The Tenax cartridges adsorb gaseous compounds and trap small particles. Apparently, it is not critical whether the subsequent thermal desorption occurs from the porous polymer or from trapped particles. Many studies have focussed on smoke particles, using high-volume sampling on filters, followed by extraction and analysis [2,8,9]. These techniques are advantageous specifically for compounds of low volatility, allowing determinations of non-reactive compounds in very low concentrations.

\section{CONCLUSIONS}

The results demonstrate very large differences in the proportions of key compounds in wood smoke for different stove devices and burning conditions. Early studies treated wood and biomass burning mainly as a uniform source of air pollutants $[2,6,8]$, and efforts have been made to find specific tracer compounds. The differences in composition are particularly important to consider when parameters are chosen for regulation of emissions, and when burning devices are constructed for minimising hazardous emissions.

\section{REFERENCES}

1. Alén R., Kuoppala E. and Oesch P., Formation of the main degradation compound groups from wood and its components during pyrolysis. J. Anal. Appl. Pyrolysis, 36, 137-148 (1996).

2. Hawthorne S.B., Krieger M.S., Miller D.J. and Mathiason M.B., Collection and quantitation of methoxylated phenol tracers for atmospheric pollution from residential wood stoves. Environ. Sci. Technol., 23, 470-475 (1989). 
3. Kjällstrand J., Ramnäs O. and Petersson G., Methoxyphenols from burning of Scandinavian forest plant materials. Chemosphere, 41, 735-741 (2000).

4. Barclay L.R.C., Xi F. and Norris J.Q., Antioxidant properties of phenolic lignin model compounds. J. Wood Chem. Technol., 17, 73-90 (1997).

5. Kjällstrand J., Methoxyphenols in smoke from biomass burning. In: Proc. of the 1st World Conf. and Exhibit. on Biomass for Energy and Industry, June 2000 Sevilla, James \& James (Science Publishers) Ltd, in press.

6. Simoneit B.R.T., Schauer J.J., Nolte C.G., Oros D.R., Elias V.O., Fraser M.P., Rogge W.F. and Cass G.R., Levoglucosan, a tracer for cellulose in biomass burning and atmospheric particles. Atmos. Environ., 33, 173-182 (1999).

7. Barrefors G. and Petersson G., Volatile hydrocarbons from domestic wood burning. Chemosphere 30, 1551-1556 (1995).

8. Hawthorne S.B., Miller D.J., Langenfeld J.J. and Krieger M.S, PM-10 high volume collection and quantitation of semi- and non-volatile phenols, methoxylated phenols, alkanes and polycyclic aromatic hydrocarbons. Environ. Sci. Technol., 26, 2251-2262 (1992).

9. Jenkins B.M., Jones A.D., Turn S.Q. and Williams R.B., Particle concentrations, gas-particle partitioning, and species intercorrelations for polycyclic aromatic hydrocarbons (PAH) emitted during biomass burning. Atmos. Environ., 30, 3825-3835 (1996).

10. Egsgaard, H. and Larsen, E., Thermal transformation of light tar - specific routes to aromatic aldehydes and PAH, In: Proc. of the 1st World Conf. and Exhibit. on Biomass for Energy and Industry, June 2000, Sevilla. James \& James (Science Publishers) Ltd, in press.

11. Hauk A., Sklorz M., Bergmann G. and Hutzinger O., Analysis and toxicity testing of combustion gases I. A new sampling unit for collection of combustion products. J. Anal. Appl. Pyrolysis, 28, 1-12 (1994).

12. Wattenberg L.W., Coccia J.B. and Lam K.T., Inhibitory effects of phenolic compounds on benzo(a)pyrene-induced Neoplasia. Cancer Res. 40, 2820-2823 (1980). 
13. Cupitt L.T., Glen W.G. and Lewtas J., Exposure and risk from ambient particle-bound pollution in an airshed dominated by residential wood combustion and mobile sources. Environ. Health. Persp., 102, 75-84 (1994).

14. Kjällstrand J. and Petersson G., Coniferyl alcohol from newsprint burning, Nordic Pulp Paper Res. J., $15,98-100,105(2000)$. 